\title{
NOTICIAS DE LIBROS
}

Juan Noemi (1), Esperanza en busca de inteligencia. Atisbos teológicos Ediciones Pontificia Universidad Católica de Chile, 2005 pp. 129

La ponencia de Jean Ladrière El cristianismo y el futuro de la razón es muy significativa para aproximarse al libro de Juan Noemi que hoy presentamos (2). A diferencia de quienes ven en la razón moderna de tipo "cartesiana" una realidad unívocamente negativa, Ladrière distingue tres significados que la razón adquiere en la Modernidad: "poder de claridad, sobre lo que es y lo que debe ser... un poder de comprensión y de juicio acerca de lo que conviene hacer"; "un cierto orden de cosas que se impone al espíritu, que este reconoce o del que al menos hace la hipótesis... por extrapolación a partir de una experiencia dada"; y "reino de figuras que se constituyen por medio de la 'poiesis', por medio de lo que podría llamarse la acción instauradora".

Es en relación a este tercer sentido, y atendiendo a lo que ha sido en concreto la historia de la reflexión y de la ciencia en la Modernidad, que este pensador habla de la esperanza de la razón moderna: "La razón, como proceso de su autoconstitución, siempre adveniente y diferida, pende del acaecer no justificable, no figurable, no representable de lo que podría revelar su sentido, de lo que ahora le da efectivamente dicho sentido. Ella es la esperanza de aquello mismo que, desde su futuro no situable, la sostiene en cuanto esperanza. En una palabra, la reflexión acerca de las modalidades de constitución de la razón científica nos lleva a concebir la estructura de la razón como estructura escatológica. Su despliegue actual está dependiendo, como anuncio, de un acontecimiento siempre por venir, ya presente $\mathrm{y}$, sin embargo, siempre esperado, en la fragilidad de una esperanza no fundamentada".

A juicio de Noemi, el diagnóstico de Ladrière comporta un acceso privilegiado a la autonomía de la razón moderna en cuanto no solo afirma la positividad que representa por sí misma, sino que también percibe una apuesta escatológica. Aquí

(1) Este libro fue presentado el 27 de septiembre en la Sala Blanca del Centro de Extensión de la Pontificia Universidad Católica de Chile.

(2) Esperanza en busca de inteligencia. Atisbos teológicos, Santiago 2005, 30ss. acontece, a juicio de Noemi, una aproximación a la razón moderna desde sí misma, como responsabilidad, lo que implica "una reevaluación del espíritu subjetivo". El teólogo chileno advierte que Ladrière, más allá del cliché de relativismo, percibe en la razón moderna una íntima responsabilidad debida a "una solicitación", que la establece "el otro y la comunidad". La razón moderna no es la negación del Otro, sino que se rige como responsabilidad ante otros, como la tarea de "obrar para constituir una comunidad auténtica, es decir, una forma efectiva de la reciprocidad. La responsabilidad primera de la acción se define con respecto a esta tarea, pero lo que se manifiesta en la ciencia tiene también valor para la razón práctica, en el sentido de que la dinámica científica hace aparecer una estructura que vuelve a encontrarse en las dinámicas de la razón práctica. En definitiva, la acción es ciertamente primera, precisamente en cuanto razón práctica, pero ella es portadora de una responsabilidad objetiva, y el sentido de esta objetividad es la relación de la acción con un devenir al cual hay que hacer advenir en la exterioridad y que pide ser asumido como deber-ser. Asumiéndose efectivamente la razón se vive como anuncio de su 'eschaton'. El estatuto de la razón práctica debe, pues, ser comprendido en la perspectiva de una estructura escatológica de la razón".

El planteo de Ladrière no supone así, en la recepción que de él realiza Noemi, un simple cambio del signo negativo por uno unívocamente positivo de la razón, pues el pensador de Lovaina manteniéndose en la lógica de la autonomía de la razón moderna, reconoce una "amenaza siempre presente" que es interior a la razón: "La acción hace la experiencia simultánea de una vocación que la llama a inscribirse en el proceso de autoconstitución de la razón por una parte y, por otra, de una amenaza siempre presente, la cual ella debe reconocer claramente que viene, en sus formas más amenazantes, de su propio interior". Y es en este momento cuando Noemi recoge de Ladrière la siguiente pregunta clave y directriz: “¿Qué papel juega entonces el cristianismo?”, en donde el teólogo subraya que se establece una premisa teológico-fundamental que no solo recuerda la de la escolástica clásica de gratia supponit naturam, sino que constituye uno de los axiomas más sugerentes de la tradición católica (y últimamente de algunos autores protestantes que Noemi recoge en su libro) que no disocia el orden 
creacional del salvífico (o dichos con palabras del propio autor, al Creador, del Salvador y el Consumador). De esta manera la siguiente frase de Ladrière se puede leer como una auténtica toma de postura teológica del autor del libro que presentamos: "La fe no es constitutiva de la existencia, la presupone; es una modalidad, según la cual puede vivirla, no es que necesariamente deba hacerlo. En este sentido ella sobreviene a la existencia, pero forzosamente lo hace insertándose en ella. Sin embargo, solo puede hacerlo en la medida en que esta se preste a ello; es necesario que pueda encontrar en la existencia un ámbito de inserción".

Nosotros creemos que Noemi ha sabido "leer" en el planteo (y hermenéuticamente hablando, sobre todo en las preguntas) de Ladrière a un perspicaz pensador que nos confronta con el real reto o desafío que la razón moderna hace a la teología y a la Iglesia.

Es precisamente en función de la perenne exigencia neotestamentaria de "dar razón" de la esperanza (v. gr. de Jesucristo, en el planteo de Noemi) ahí donde esta sea solicitada, que entendemos la tarea de Noemi como un servicio a la misión de la Iglesia, precisamente ahí donde descubre en las preguntas del hombre "ámbitos de inserción" de la fe en estructuras que no le pueden ser totalmente ajenas al dato revelado, si no se quiere pagar el precio que tuvo que cancelar la teología que no supo interpretar del todo el axioma escolástico de que "la gracia presupone la naturaleza y la perfecciona", que, en la Modernidad se puede releer como una naturaleza de corte histórico en la cual la razón no se erige unívocamente como un instrumento autónomo e inmanente, sino como una posibilidad otorgada al hombre $-\mathrm{y}$ en los términos teológicos que utiliza Noemi tendríamos que hablar aquí de un don del Creadorque, a través de la piedad que supone el preguntar para el pensar, escucha la palabra interior que nunca deja de implicarnos en el horizonte más amplio del interrogante por el ser en su devenir histórico de cara a un siempre querer y anhelar "ser-más" que solo puede ser recibido en acción de gracias. Pannenberg en sus cuidadosos estudios histórico-teológicos ha llamado la atención cómo desde las disputas de los primeros concilios, la teología siempre ha tenido este carácter "misional", es decir, encontrar en lo que hemos llamado "ámbito de inserción" las "condiciones mínimas de posibilidad" del lenguaje teológico, que aunque provisorias e incompletas, son necesarias para que la teología no devenga "glosolalia" y traicione su rol misional.

Hoy en día, como lo recordó Vatimo en su visita a Chile el año pasado, la hermenéutica se ha convertido en la nueva koiné del pensar y de las ciencias. Mientras preparábamos esta presentación, hemos estado leyendo intensamente a Gadamer y hemos "encontrado" en su reflexión un “ámbito de inserción" de la fe en el plano de la esperanza que se ha revelado como un interesante conjunto de preguntas que tocan, a mi juicio, el meollo del planteo de Noemi.

Así, propongo aquilatar el planteo teológico de la obra que presentamos por las posibilidades que tiene de entrar en diálogo con quizá uno de los ensayos que mejor nos ha señalado la textura y texto de la razón moderna, como lo es la hermenéutica de Gadamer. Al final señalaremos algunos desafíos a los que nos invita Noemi.

La filosofía tardía de Gadamer, en la formulación balbuciente que cobró en conversaciones con medios periodísticos alemanes en sus últimos años, era sin duda una filosofía de la esperanza. En una entrevista que concedió con ocasión de su 102 cumpleaños, el 11 de febrero de 2002, pocas semanas antes de su fallecimiento, y que fue reproducida en casi todos los diarios y periódicos locales alemanes, confirmaba una intuición que se había convertido en un leitmotiv de los últimos años de su vida: "La única frase que sin restricciones querría seguir defendiendo es que los hombres no pueden vivir sin esperanza". Se comprende que los diarios la destacaran como titular: "Principio Esperanza. Hans-Georg Gadamer cumple 102 años". Para el sentir general -como para su propia autocomprensión- Gadamer se había convertido en el portavoz del "principio esperanza".

A primera vista, esto resulta más bien sorprendente. Porque bajo el título Principio Esperanza, quien más de inmediato viene a la mente es un autor como Ernst Bloch (que por lo demás fue en 1948-49 sucesor de Gadamer en Leipzig) o el teólogo de Tubinga Jürgen Moltmann (ambos autores, por cierto, muy influyentes en los planteos de Noemi sobre la esperanza). Pero ¿le cuadra esto a Gadamer? Mas: ¿por qué era esta "la única frase" que Gadamer quería seguir defendiendo sin restricciones? A uno se le ocurrirían otras frases más representativas del pensador de Heidelberg, por ejemplo: "el ser que puede ser comprendido es lenguaje" (3); "A decir verdad, no nos pertenece la historia a nosotros, somos nosotros los que le pertenecemos" (4); "El fenómeno hermenéutico originario es que no puede haber ninguna afirmación que no se pueda entender como respuesta a una pregunta" (5) o, como más tarde se formuló a menudo: "El alma de la hermenéutica consiste en

(3) Gesammelte Werke, vol. I, Wahrheit und Methode, Tubinga 1985ss, 478, que es la "conclusión" de Verdad y Método.

(4) Ibíd, 281, que es la tesis principal de la segunda parte de su obra capital.

(5) Gesammelte Werke, vol. II, Wahrheit und Methode, Ergänzungen, Tubinga 1985ss, 226. 
que el otro puede tener razón" (6). Pero a ningún lector de Verdad y Método, o de las Obras Completas, se le ocurriría pensar que la máxima singularmente destacada es "que los hombres no pueden vivir sin esperanza”. En la obra capital de Gadamer, del año 1960, no se hace mención alguna de la esperanza. Todo lo contrario: la obra pareció insistir mucho más en la determinación de la conciencia por el pasado y la historia. No en último término, Gadamer quería marcar en ella una diferencia respecto a su maestro, Heidegger, cuyo punto de partida parecía estribar mucho más en la futuridad del Dasein o en un "nuevo comienzo".

Además, Gadamer ha hablado raras veces de la esperanza en un sentido estrictamente "religioso", tal como se conoce, por ejemplo, en la tradición cristiana, donde según la Primera Carta a los Corintios $(13,15)$ la esperanza es una de las tres grandes "virtudes teologales", junto al amor y la fe. Este horizonte religioso-cristiano le era más bien ajeno a Gadamer.

El tomó más bien su inspiración más importante del Prometeo del trágico griego Esquilo. Como es sabido, en la mitología griega Prometeo pasa por ser el que dispensó a los hombres el fuego y las artes, los grandes medios de su autoliberación. Sin embargo, según Esquilo, tal como lo leía Gadamer, Prometeo había proporcionado a los hombres algo más esencial: les había quitado el conocimiento de la hora de su muerte. Antes de que Prometeo los liberara, expone Esquilo, los hombres llevaban una existencia desdichada a manera de larvas que vivían sepultadas en cavernas y aguardaban su suerte inevitable. No tenían la más mínima esperanza. Cuando vino Prometeo se extinguió este conocimiento sobre la hora de su muerte. Gracias a ello, los hombres empezaron a salir de sus cavernas, a construir casas y calles, a fundar ciudades y a cultivar las artes y las ciencias. Porque ahora tenían esperanza y futuro. En griego a esta esperanza se la llama elpis. No significa una esperanza en un más allá, sino simplemente el coraje, el optimismo vital, la confianza en la vida, que nos depara la posibilidad de emprender cosas y realizar proyectos. Nos proyectamos en el futuro porque somos seres que viven de esperanza. Pero esta esperanza presupone, como podemos saber por Esquilo, cierto olvido de la fatalidad. ¿No tiene que olvidar el hombre su mortalidad para poder vivir? En este aspecto se distinguió también Gadamer de su maestro Heidegger, quien tendía a caracterizar la represión de la muerte como una forma de inautenticidad para contraponerle una decidida marcha a la muerte. Quizá esto le resultaba a Gadamer demasiado abstracto, demasiado rebuscado, incluso inhumano. El olvido le parecía mucho más esencial y natural.

Es esta "esperanza", la esperanza en dirección al futuro, el optimismo vital, lo que Gadamer saludaba en Prometeo, porque veía en ella algo distinto de un fenómeno negativo de represión. Se- gún él, es la condición fundamental de la conditio humana y de nuestras posibilidades de comprender, en la medida en que la comprensión -como también enseñó Heidegger- tiene carácter de proyecto (Entwurf). Solo se comprende algo en $d i$ rección hacia algo, como, por ejemplo, se comprende lo particular en referencia a un todo, que nunca está dado de modo objetual y que, sin embargo, constituye el horizonte de toda comprensión. Es lo que sucede con el sentido a que aspira nuestra comprensión y nuestra vida. Se trata primariamente de un sentido de orientación, de una esperanza de sentido, sin la cual la vida humana es irrealizable (7).

Si se examina más de cerca, se advierte que este sentido de esperanza quizá no es tan ajeno al espíritu de Verdad y Método como podría parecer a primera vista. La pretensión fundamental de la obra es dar a conocer una experiencia de la verdad que va más allá del ámbito que está bajo el control del método científico. La verdad de los métodos se ha de apreciar en alto grado, pero no es la única para un ser que espera y proyecta, que es justamente lo que somos nosotros. No toda verdad se deja demostrar, comprobar y medir. Existe también la verdad vital, de la que todos nos nutrimos y que quizá es más fundamental (cuanto más que la misma esperanza de una verdad científica se ha de apoyar en ella). Es esta verdad la que Verdad y Método quiso recordar de la mano del arte, de la historia y del lenguaje. Aquí se nos comunica una verdad, exponía Gadamer, que no tiene nada que ver con la medición, la verificación o la objetivación. Sobre ella nos informaba Verdad y Método que "va más allá de ámbito controlado por la metodología científica" y preguntaba: "¿Qué tipo de conocimiento y qué tipo de verdad son esos?" (8).

Hoy, retrospectivamente, podemos decir que esta verdad es una verdad de la esperanza. Porque cabe aplicar por igual al arte, la historia y la lengua el que la experiencia de sentido testimoniada por ellos tiene algo que ver con la esperanza y la ampliación de horizontes. Toda obra de arte que ofrece una representación del mundo, es decir, que muestra el mundo tal como es en su esencia $\mathrm{y}$, en virtud de ello, le otorga un incremento entitativo, es una especie de promesa, una promesse de bonheur: me abre un mundo (Paul Ricoeur) (9)

(6) Cf. Über die Verborgenheit der Gesundheit, Frankfurt 1993, 109ss.

(7) Cf. Hermeneutische Entwurfe, Tubinga 2000, 218: "La esperanza es una estructura fundamental de nuestra conciencia vital, sin la cual apenas podríamos soportar las cargas de la vida".

(8) Gesammelte Werke, vol. I, 1.

(9) Cf. La mémoire, I'histoire, l'oubli, Paris, Seuil, 2001, 367ss. 
al que me puedo proyectar. ¿Quién podría objetivar científicamente esta experiencia? Es únicamente una pretensión que reclama una respuesta, que configure mi vida y la puede cambiar. Toda obra de arte, dice Gadamer con Rilke, me hace un requerimiento: ¡debes cambiar tu vida! Ese es el enigma, el milagro y la verdad del arte. Transforma en una figura duradera una esperanza vital, una experiencia del mundo digna de conservación y de consideración, que viene a ser una prenda de lo posible.

Esto es válido por de pronto de la historia, la gran memoria y maestra de la humanidad. Es la historia la que nos enseña, de un modo que ninguna ciencia metódica es capaz de demostrar, que son los hombres, que pueden realmente, y también que no pueden. La historia del mundo, decía Hegel (10), pone ante nuestros ojos el progreso en la conciencia de la libertad. Esta historia es también la de las esperanzas de la humanidad, de las irreversibles como de las destruidas. Con esta esperanza, la esperanza en el hombre y en su futuro, por inseguro que sea, estudiamos también la historia. ¿Qué es lo que impulsó a los hombres en aquellas circunstancias si no fue la esperanza, que inhabita todos nuestros proyectos de sentido?

Lo mismo cabe decir del lenguaje. De él decía Gadamer que su propósito es el entendimiento. No es meramente un "instrumento" del pensamiento, es el elemento originario de nuestras posibilidades de hacemos entender y de entendemos a nosotros mismos.

Esta esperanza es, naturalmente, quizá solo una esperanza, pero sin ella no se da ningún lenguaje. Y esta esperanza es también la esperanza de que el mundo está presente en la palabra. Esta presencia del mundo en la palabra es tan originaria, tan primitiva, que es imposible analizar la lengua misma sin presuponerla. Ya de siempre, inmemorialmente, ha dimensionado el horizonte de lo inteligible. Toda fundamentacion, toda comprensión, se apoya en ella, en la esperanza en ella (11). En el arte, en la historia y en la lengua se constituyen todas nuestras posibilidades y oportunidades de comprensión, incluso las de la ciencia, en cuanto que no se la puede pensar sin retórica, historia y lenguaje.

(10) Cf. Vorlesungen über die Geschichte der Philosophie, Frankfurt 1971, 32.

(11) En el planteo de Noemi se puede concluir que la verdad vive, por así decir, de la esperanza, es decir, en la presunción y la expectación de sí misma. La verdad hermenéutica, que no quiere ser la verdad total, se muestra como obligatoria y al propio tiempo como problemática, porque sabe de su problematismo y de la necesidad de su obligatoriedad.
Por tanto, no se da solo la verdad metódica, que supuestamente solo comprende en la medida en que algo se deja dominar y controlar. ¿Qué dominamos efectivamente? Muy poco, a la postre. Como explica Gadamer en la penúltima línea de su obra capital, los límites del "método" no son en absoluto los de la verdad y los de nuestra comprensión (12). Existe también una verdad que se debe a la Wirkungsgeschichte, es decir, y a la letra, a la historia que influye en nosotros y a la esperanza alimentada por ella, sin la cual no podríamos vivir, aun cuando no la podamos fundar. Llegamos ya demasiado tarde a esta tarea. Por ello, insiste Gadamer, la historicidad no constituye en absoluto una condición restrictiva, sino una condición positiva para el conocimiento de la verdad (13) (expresión que por cierto encontramos, en otras formulaciones, en el texto de Noemi). En esto consistió, según Gadamer, la enorme y admirable brecha que abrió la hermenéutica heideggeriana de la facticidad: en que la historicidad ya no, o no solo, se debía considerar como un límite que hay que superar. Solo puede sentirse como límite desde el observatorio de una verdad absoluta, que ya no tendría nada que ver con nuestra historicidad, ni con nuestras posibilidades lingüísticas. Tal verdad puede dejarse tranquilamente como dice Diótima en El Banquete- a la divinidad. En esto es Gadamer muy hondamente platónico. La verdad no es solo asunto de método y seguridad. Es también la verdad que nos sostiene, de la que desde siempre nos alimentamos, la verdad hermenéutica par excellence, la verdad de la esperanza. ¿Lo que constituye finalmente la "verdadera infinitud" como horizonte de nuestra esperanza como plantea Noemi en su texto?

Si volvemos al planteo de Noemi, ¿cómo podemos formular hoy frente a esta nueva koiné, que es la hermenéutica, la razón de nuestra esperanza?, ¿ofrece esta koiné "ámbitos de inserción”, "condiciones mínimas" para el lenguaje de la fe? Nosotros creemos que la obra de Noemi otorga la oportunidad de dialogar desde la temática de la esperanza, tan profundamente humana como nos han señalado Ladrière y Gadamer entre otros, y tan radicalmente teológica.

¿Es posible hablar hoy del Dios de Jesucristo, el Dios del Espíritu, como de un objeto abstracto y trascendente (en un sentido abusivo de la misma palabra trascendente)?, ¿no será más bien este Dios la esperanza histórica y concreta inscrita en toda la creación, que al interior de la estructura formal del pensamiento de Noemi, es decir, de "identidad y diferencia", y no solo de "paradoja", se nos presenta como realidad trascendente (en el sentido auténtico de la palabra, es decir, como ex-

(12) Cf. Gesammelte Werke, vol. I, 494

(13) Cf. Gesammelte Werke, vol. II, 103. 
plica nuestro autor trascendencia no es mera negación de la inmanencia, sino fundamentación de la misma. Lo inmanente queda religado en su ser a lo trascendente) que acontece en la inmanencia de la historia humana? ¿No serán las preguntas por el sentido auténtico de la libertad, la provocación del arte, la experiencia de la historicidad, el redescubrimiento de la esperanza como principio humano básico, la insatisfacción del pensar sin una referencia a un todo que garantice la verdad de lo contingente y finito y, al revés, de un todo que implique la necesaria asunción de lo múltiple, las que finalmente nos revelan a una esperanza que busca inteligencia, que la fe descubre como naturaleza creada en busca de una anticipación cada vez mayor, un reto a los teólogos en su dimensión misionera?

Todas estas preguntas son solo interrogantes y no la respuesta definitiva, ¿pero no implica toda verdadera pregunta una anticipación de aquello que se anhela? Y aquello que se anhela, aunque solo sea a modo de "prenda" de experiencia del "todavía no" la teología tiene la ardua tarea de pensarlo desde Jesucristo junto a la experiencia trinitaria del Espíritu y del Padre.

La teología de Noemi sostiene, fiel al Himno a los Colosenses, consecuentemente que todo ha sido creado teniendo como modelo a Jesucristo. Si la teología no descubre en la creación una coestructura trinitario-cristológica como anticipación de la esperanza definitiva, ¿no está renun- ciando a lo que es la salvación, que no es tanto salvar "de" sin ante todo profecía del hombre, permitir a este su realización plena? ¿Están los teólogos preparados para hablar de Jesucristo como revelación de la existencia como pro-existencia a partir de un instrumental filosófico-teológico que haga justicia a la revelación en sus tres momentos: creación-salvación-redención? y, por último, ¿está la teología preparada para señalar qué tiene que ver todo esto con una invitación a una "vida buena", que luego, de alguna manera, se puede verificar? ¿Puede haber "vida buena” sin un sentido total de realidad que se me anticipa en mi praxis actual?, ¿cómo se lee esto teológicamente desde la existencia proactiva de Jesucristo? ¿Cómo se lee esto desde la Iglesia?

En fin, pensamos que el libro de Juan Noemi es una ayuda y un reto a la misión de la Iglesia en Chile, porque razona su fe sin concesiones. Es una fe, "paradójicamente" algo débil, pues depende de la filosofía (más concretamente de los mundos que abren pensadores como Ladrière y Gadamer), la sociología (por ejemplo Luhmann), etc. y, finalmente de la razón, ¿pero no consistirá por eso, en su capacidad de recibir las preguntas que nacen de la busca de esperanza toda su fortaleza?

Queda por último agradecer la lograda edición de las "Ediciones de la Pontificia Universidad Católica de Chile".

Carlos Ignacio Casale Rolle 